\title{
Internet of Things in Marine Environment Monitoring: A Review
}

\author{
Guobao Xu ${ }^{1}\left(\mathbb{D}\right.$, Yanjun $\mathrm{Shi}^{2}$, Xueyan $\mathrm{Sun}^{3}$ and Weiming Shen ${ }^{3, *(\mathbb{D}}$ \\ 1 School of Electronics and Information Engineering, Guangdong Ocean University, Zhanjiang 524088, China; \\ xuguobao@126.com \\ 2 School of Mechanical Engineering, Dalian University of Technology, Dalian 116024, China; syj@dlut.edu.cn \\ 3 State Key Lab of Digital Manufacturing Equipment and Technology, Huazhong University of Science \& \\ Technology, Wuhan 430074, China; sunxueyanxy@163.com \\ * Correspondence: wshen@ieee.org; Tel.: +86-27-8754-3129
}

Received: 5 March 2019; Accepted: 6 April 2019; Published: 10 April 2019

check for updates

\begin{abstract}
Marine environment monitoring has attracted more and more attention due to the growing concern about climate change. During the past couple of decades, advanced information and communication technologies have been applied to the development of various marine environment monitoring systems. Among others, the Internet of Things (IoT) has been playing an important role in this area. This paper presents a review of the application of the Internet of Things in the field of marine environment monitoring. New technologies including advanced Big Data analytics and their applications in this area are briefly reviewed. It also discusses key research challenges and opportunities in this area, including the potential application of IoT and Big Data in marine environment protection.
\end{abstract}

Keywords: Internet of Things; Big Data; wireless sensor networks; marine environment monitoring

\section{Introduction}

Although the Internet of Things (IoT) has been defined in various perspectives, there is a common version that is widely accepted by scholars as follows: IoT is a dynamic global network infrastructure with self-configuring capabilities based on standard and interoperable communication protocols, where physical and virtual "things" have identities, physical attributes, and virtual personalities and use intelligent interfaces, and are seamlessly integrated into the information network [1]. Recently, IoT has been widely accepted as a promising paradigm that can transform our society and industry. It can achieve the seamless integration of various devices equipped with sensing, identification, processing, communication, actuation, and networking capabilities [2]. A wireless sensor network (WSN) plays a key role in IoT. It consists of a large number of distributed sensors interconnected through wireless links for physical and environmental monitoring purposes. On the other hand, Big Data is considered as an emerging technology and has become a very active research area, primarily involving topics related to data mining, machine learning, database, and distributed computing.

During the past couple of decades, wireless sensor networks (WSNs), as a subset of IoT, have been widely utilized in a variety of smart applications and services, including smart home [3], smart building [4,5], smart transportation [6,7], smart industrial automation [8,9], smart healthcare [10], smart grids [11], and smart cities [12]. Similar IoT-based technologies can certainly be applied to the monitoring and protection of marine environments.

With the development of our society and economy, the marine environment has drawn increasing attention from scientists and scholars. Conventional marine environment monitoring systems such as oceanographic and hydrographic research vessels are very expensive. Their data collection and 
analysis processes are time-consuming and the collected data have a low resolution. The Internet of Things (IoT) has been evolved from wireless sensor networks (WSNs). Compared with WSNs, IoT has much stronger data processing capabilities, enabling intelligent control of objects.

In a typical IoT-based marine environment monitoring system, different sensors are deployed to measure and monitor various physical and chemical parameters like water temperature and pressure, wind direction and speed, salinity, turbidity, $\mathrm{pH}$, oxygen density, and chlorophyll levels. An advanced IoT-based marine environment monitoring and protection system would also be able to control some objects, devices, or equipment within the monitored marine environment, in order to adjust some physical and chemical parameters so as to improve the marine environment.

While the design, development, and deployment of an IoT-based marine environment monitoring and protection system is needed to address some critical issues including autonomy, adaptability, scalability, simplicity, and self-healing $[13,14]$, following requirements specific to the harsh marine environments should be considered [15]:

(1) High water resistance: Sensor and actuator nodes need to have very high levels of water resistance;

(2) Strong robustness in hardware: Hardware or equipment needs stronger robustness due to the aggressive and complex marine environment with currents, waves, tides, typhoons, etc.;

(3) Low energy consumption and energy harvesting: Energy conservation and harvesting measures need to be considered due to long communication distances and an environment in constant motion;

(4) Stability of Radio signal: Special techniques may be required to ensure the stability of radio signals since the oscillation of the radio antenna can cause an unstable line-of-sight between transmitters and receivers [16] and bad weather conditions can also affect the stability of radio signals;

(5) Other issues: Devices and sensor nodes should be highly reliable because of the difficult deployment and maintenance; the need for buoy and mooring devices; sensor coverage needs to be carefully calculated because of large areas [17]; equipment should be designed against possible acts of vandalism.

We conducted a comprehensive review of WSN applications in marine environment monitoring in 2014 [18]. When we planned and started this updated review, we wanted to expand the scope from WSN to IoT and to cover the protection aspect in addition to the monitoring because of the characteristics of IoT not only on sensing but also on actuation. However, we did not find enough references related to protection. In this paper, we do not consider the protection aspect as a focus but keep the related discussions. We envision the protection from two perspectives: (1) Results from the advanced data analytics based on the data collected by the monitoring system can be fed back to the marine environment management agencies/control centers for quick decision making and real time manual interventions in order to protect the marine environment from some disasters (e.g., oil spills and bad weather damages); (2) some autonomous vessels or other devices (actuators) can also automatically and quickly react to disasters and other events in order to protect the marine environment. Similarly, we wanted to cover the Big Data analytics and its applications to marine environment monitoring and protection, but we did not find sufficient references. Therefore, we did not make the Big Data a focus of this paper. However, we strongly believe that Big Data analytics will play a more and more important role in this area in the future.

The remainder of the paper is organized as follows: Section 2 provides an overview of the fundamentals of IoT-based marine environment monitoring systems; Section 3 presents a summary of some related projects and systems under five application areas; Section 4 reviews a few new technologies applied in the marine environment monitoring systems; Section 5 addresses some research challenges and opportunities in this area; Section 6 provides some concluding remarks. 


\section{Overview of IoT in Marine Environment Monitoring}

This section provides an overview of IoT in marine environment monitoring, including various applications, common system architectures, typical sensing nodes and sensing parameters, and related wireless communication technologies.

\subsection{IoT-Based Marine Environment Monitoring Applications}

IoT-based marine environment monitoring application areas include: (1) Ocean sensing and monitoring; (2) water quality monitoring; (3) coral reef monitoring; (4) marine (either offshore or deep-sea) fish farm monitoring; (5) wave and current monitoring. Different applications use different IoT system architectures, sensing and control technologies, and communication technologies.

An ocean sensing and monitoring system is a general marine environment monitoring system, which existed for a long time, previously using oceanographic and hydrographic research vessels. A water quality monitoring system usually monitors water conditions and qualities, including water temperature, $\mathrm{pH}$, turbidity, conductivity, and dissolved oxygen (DO) for ocean bays, lakes, rivers, and other water bodies. A coral reef monitoring system typically monitors coral reef habitats and the surrounding environments. A marine fish farm monitoring system monitors water conditions and qualities including temperature and $\mathrm{pH}$, measures the amount of fecal waste and uneaten feed for a fish farm, as well as fish conditions and activities including the number of dead fishes. A wave and current monitoring system measures waves and currents for safe and secure waterway navigations.

\subsection{Common IoT-Based System Architectures for Marine Environment Monitoring and Protection}

The Internet of Things is usually to achieve "knowing, thinkable, and controllable" to the surrounding world [19], which means that the IoT is able to perceive, think, and control the world by collecting, processing, and analyzing the data of the world. It can make intelligent judgments that impact on the outside world. IoT researchers have proposed different IoT system architectures in the research literature. Among them, a five layered system architecture was proposed by Antao et al. [20]. Similarly, we also believe that a typical IoT-based marine environment monitoring and protection system has five layers: Perception and execution layer, transmission layer, data pre-processing layer, application layer, and business layer, as shown in Figure 1.

(1) Perception and Execution Layer

The perception and execution layer is the bottom layer of the architecture. It includes sensor and actuator devices, with the objective of sensor data collection and command actuation. In IoT-based marine environment monitoring and protection systems, this layer can also include GPS sensors, energy harvesting devices, in addition to regular water condition and quality monitoring sensors. Note that most existing marine environment monitoring systems do not have any execution functions and therefore do not include actuators.

(2) Data Transmission Layer

The main function of the data transmission layer is to transmit various collected data to the data processing layer via communication networks, mostly mobile or wireless communication networks. At the same time, control measures made by users or intelligent applications (reference engines) are transferred from the application layer to the perception and execution layer, thus that corresponding devices or actuators can take required actions (such as device repositioning, increasing or decreasing temperature settings, releasing food in fish farms).

(3) Data Pre-Processing Layer

The data pre-processing layer is in the middle of the IoT system architecture, where the raw data received can be stored and pre-processed, using advanced data mining technologies. It also completes 
information aggregation or disaggregation, data cleaning and fitting or screening, sharing as needed, and sometimes it triggers alerts or warnings based on pre-defined rules.

(4) Application Layer

The application layer provides services according to different applications requested by users. For example, it provides water condition and quality data as well as the amount of fecal waste and uneaten feed for a fish farm. The main purpose of this layer is to provide smart application services to meet users' needs. In IoT-based marine environments, this later covers water quality monitoring, coral reef monitoring, marine (either offshore or deep-sea) fish farm monitoring, wave and current monitoring [21-23].

(5) Business Layer

The business layer is the top layer and manages the overall IoT system activities and services, including creating business models, business logic flowcharts, graphic representations, according to the data received from the application layer. It also monitors and verifies outputs of the other four layers according to the business models in order to enhance services and maintain users' privacy [21,23].

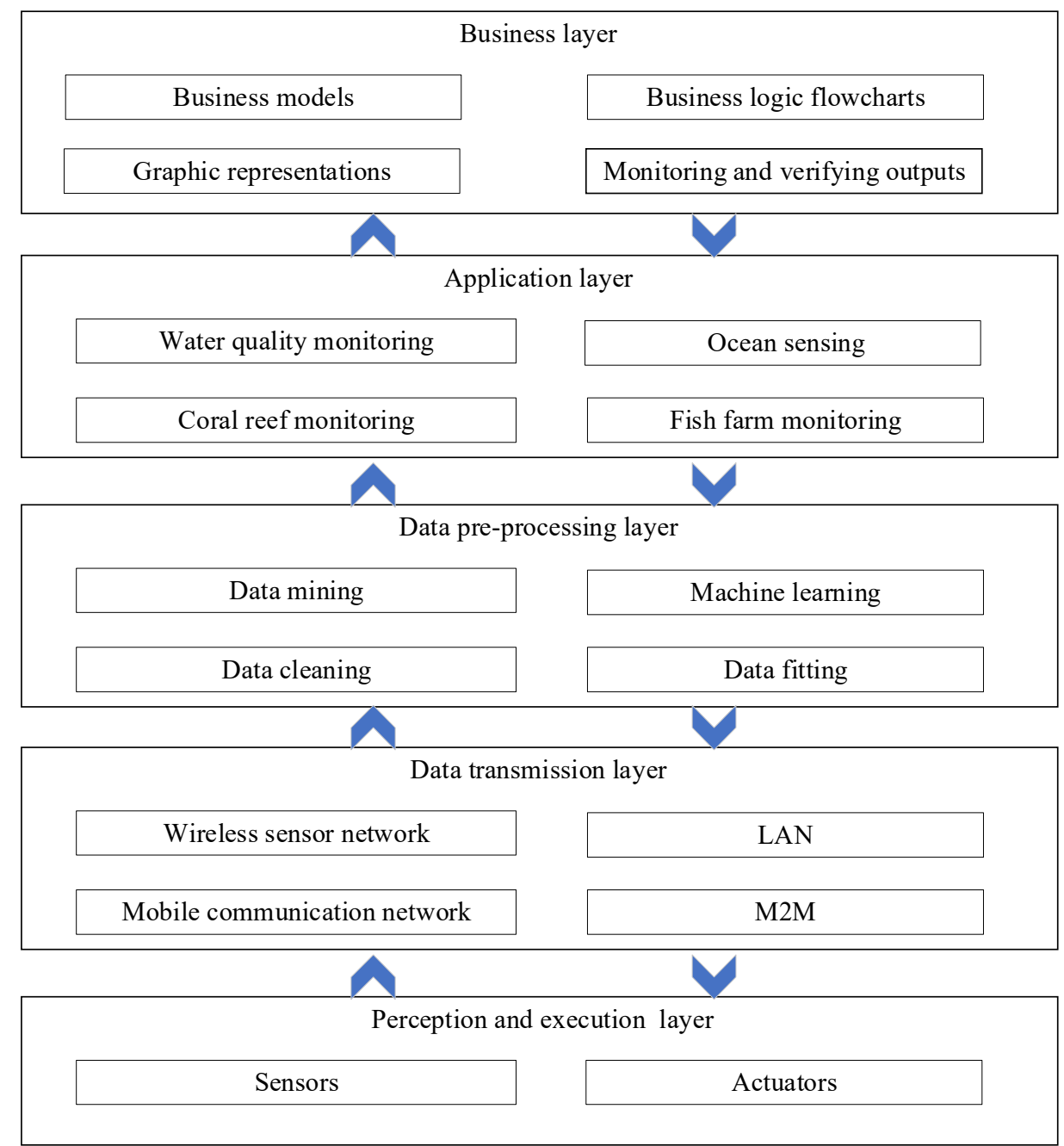

Figure 1. Common layered architecture for Internet of Things (IoT)-based marine environment monitoring and protection applications.

Such a layered system architecture provides a good picture of the data/information flow in IoT-based marine environment monitoring and protection systems. Figure 2 shows a common physical 
architecture of IoT-based marine environment monitoring and protection systems. It includes sensor nodes and actuator nodes, sink nodes, a base station, a system server, and user terminals. Sensor nodes are used to sense and monitor environmental parameters such as water temperature and $\mathrm{pH}$, salinity, turbidity, oxygen density, and chlorophyll levels, and transmit the collected data to sink nodes via ZigBee or some other wireless communication protocols. Actuator nodes execute commands from the upper layers. Communication between a sink node and sensor or actuator nodes is usually point-to-point. A sink node collects data from a group of sensor nodes and sends collected data to the base station or passes execution commands from upper layers to actuator notes, via mobile communication networks (2G/3G/4G). The base station is connected to a system server through the Internet. The system server stores and processes the received data from the base station, completes data analyses according to corresponding applications, sends commands to actuator nodes according to the pre-defined rules as appropriate. Various kinds of user terminals (desktops, laptops, pads, and smart phones, etc.) connect users to the system server over the Internet (including mobile Internet).

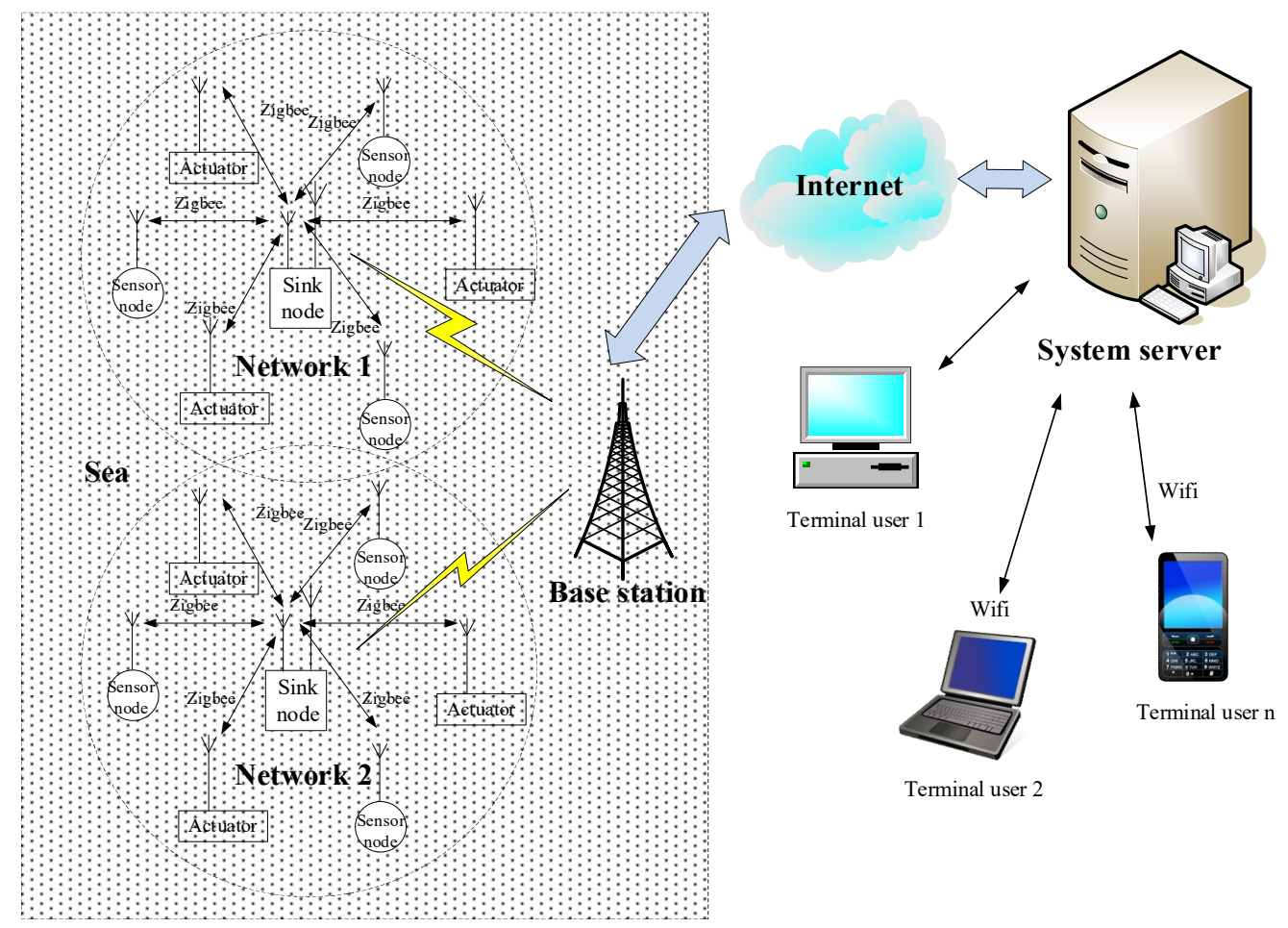

Figure 2. Common physical architecture of IoT-based marine environment monitoring and protection systems.

The design and development of a durable and scalable IoT system for marine environment monitoring and protection should carefully consider a number of factors: The harsh marine environment, the communication protocols and network topology, the number and distribution of nodes, buoys and mooring systems, oceanographic sensors, energy supply and harvesting options, and so on.

As described above, an IoT system consists of many sensor and actuator nodes and a gateway for the connection to the Internet. Usually, sensor and actuator nodes are organized into a connected network according to a certain topology. Physical topology and density are entirely dependent on applications [24], therefore the design and development of an IoT system need to consider its application and deployment environment. Even though more sensors can be densely deployed to enhance data availability and accuracy, a dense deployment also brings negative issues: High energy consumption, data collisions, and interferences, etc. [25]. Sensor nodes normally have four typical kinds of network topologies: Linear, star, cluster/tree, and mesh topologies, as shown in Figure 3. 
While we have discussed in detail the star, cluster/tree, and mesh topologies in reference [18], the linear topology is a series connection of all the nodes. Its main advantage is that it has a simple structure thus that the cost is relatively low. As a consequence, the transmission volume is large, and the speed is slow.
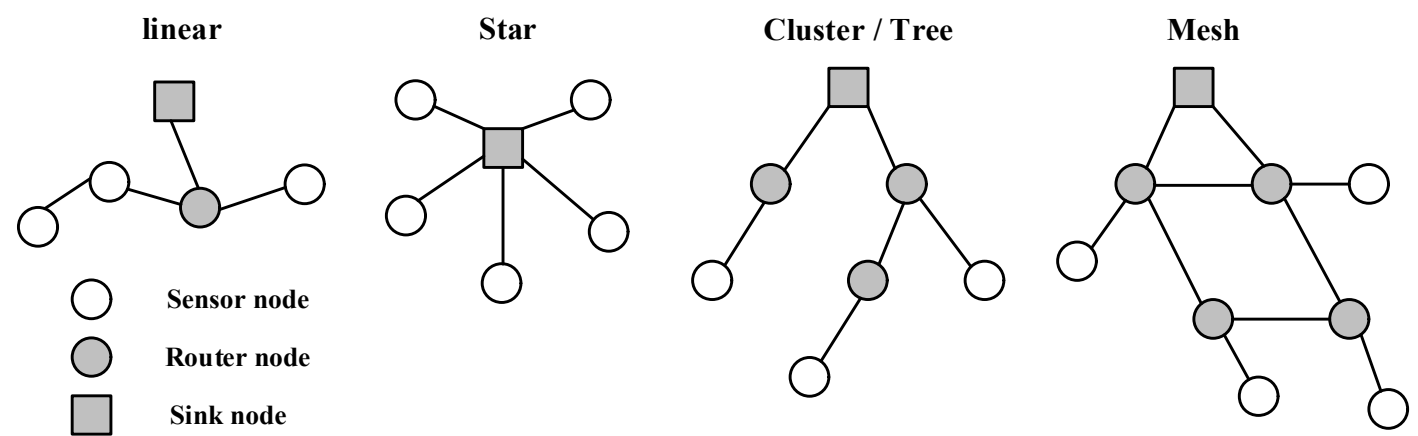

Figure 3. Typical wireless sensor network topologies.

The selection of a right network topology for a particular application depends on the amount and frequency of data to be transmitted, the distance of data transmission, the requirement of battery life as required for maintenance, and the mobility of the sensor nodes [26]. On the other hand, the physical network topology of an IoT system may change during its operation due to its energy availability, node position variations, equipment or sensor malfunction, node reachability (due to noise, severe weathers, moving obstacles, etc.), and task details of sensor nodes [27].

\subsection{A General Marine Environment Monitoring Sensor Node}

The general architecture of a marine environment monitoring sensor node is shown in Figure 4. It typically has a buoy device to protect electronic devices against water, and consists of the following four main modules [28]: A sensing module, a microcontroller, a wireless transceiver module, and a power supply module.

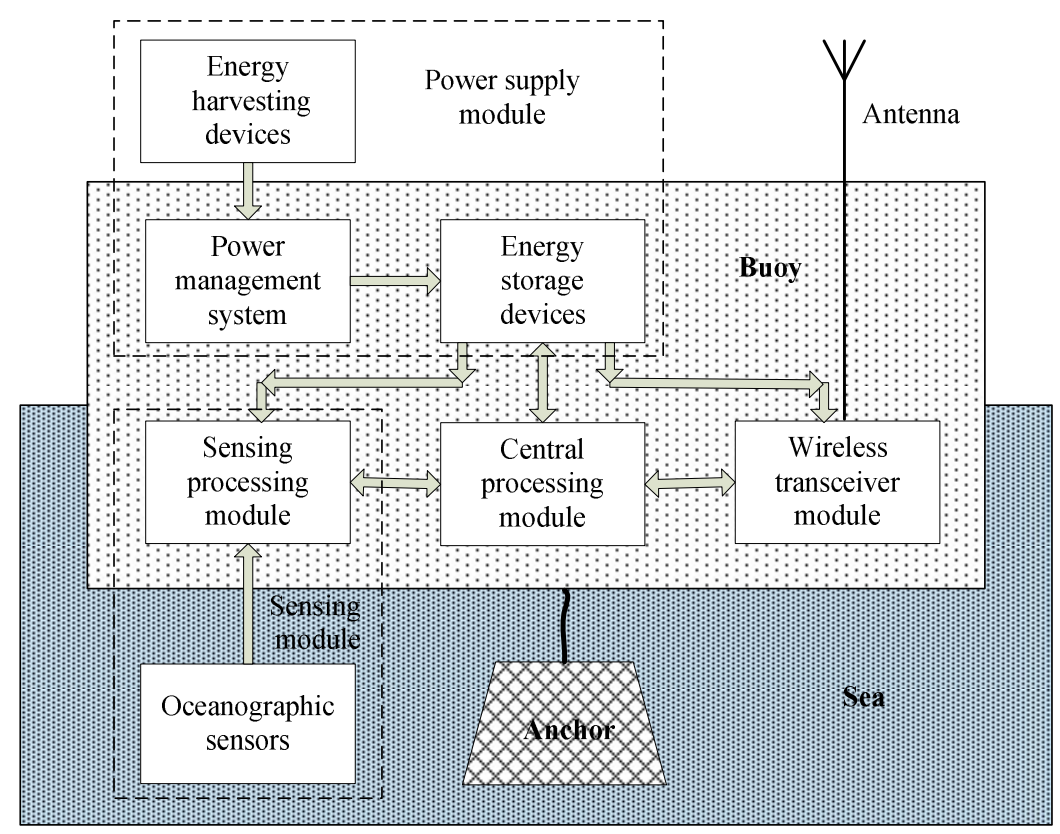

Figure 4. General architecture of a marine environment monitoring sensor node. 
The sensing module obtains the environmental and equipment status (with associated amplifiers and analog-to-digital (A/D) converters). The microcontroller receives the data from the sensor and processes the data accordingly. A wireless transceiver module includes a radio frequency (RF) transceiver and an antenna. A power supply module includes energy storage devices (like rechargeable batteries), and a power management system with energy harvesting devices, which can be a solar panel, a wind energy harvesting device, a tidal power generator, or a seawater power generator. The buoy has an anchor to prevent it from moving.

\subsection{Typical Sensors and Sensing Parameters}

Sensors are used to respond to changes in their environments by producing electrical signals in the form of electrical voltage, current, or frequency [29]. There are typically two kinds of sensors: Physical sensors and chemical sensors. Physical sensors are used to measure different physical parameters like temperature, humidity, pressure, wind speed, and wind direction. Chemical sensors are used to measure various chemical parameters like salinity, turbidity, $\mathrm{pH}$, nitrate, chlorophyll, and dissolved oxygen (DO). Details can be found in reference [18]. Decisions on the selection of sensors are made according to requirements related to the deployment area and season, measurement range, accuracy, resolution, and power consumption.

\subsection{Wireless Communication Technologies}

A sensor node requires a radio module for wireless communication. The access network, with a communication range from a few hundred meters to several kilometers, includes all the devices between the backbone network and user terminals.

For the IoT-based marine environment monitoring and protection systems, wireless communication networks have different requirements than other applications, because of the following reasons:

(1) Reliability: Radio antenna oscillations and bad ocean weather conditions can cause instability of radio signals.

(2) Energy efficiency: Low power consumption is the key to supporting long-flow and reduced maintenance costs in stand-alone battery-powered equipment. This is particularly critical for devices deployed in remote offshore areas that are difficult and costly to replace.

According to the current requirements for IoT applications, the development of wireless communication technologies has already made significant progresses. Various wireless communication standards and technologies have been proposed and developed, including WiFi, ZigBee, Bluetooth, GPRS, GSM, and WiMAX. A summary and brief comparison of these communication standards and technologies can be found be in our previous survey paper [18]. Typically, multiple wireless communication technologies are used in an IoT-based marine environment monitoring and protection system. In some specific applications, underwater acoustic communication technologies are used for data collection and communication among underwater marine environment sensors [30-33]. Generally, a longer-range communication consumes more energy. Selection of the most appropriate wireless communication technology for an application depends on the transmitted data volume, transmission frequency, transmission distance, and available power supply.

\section{A Review of Existing Marine Environment Monitoring Projects and Systems}

Various systems have been developed and deployed for marine environment monitoring during the past couple of decades. Table 1 summarizes the features of reviewed projects and systems under five different application areas as defined in Section 2.1. For completeness and consistency, we kept all the projects and systems summarized in our previous survey [18] and added more from the recent research literature. 
Table 1. Summary of existing marine environment monitoring projects and systems.

\begin{tabular}{|c|c|c|c|c|c|c|}
\hline Reference & Country & Sensing Parameters & Comm. Protocols & Buoy & $\begin{array}{c}\text { Energy } \\
\text { Harvesting }\end{array}$ & Key Features (Including Testing and Deployment) \\
\hline \multicolumn{7}{|c|}{ Application Area: Ocean Sensing and Monitoring } \\
\hline Perez et al. [34] & Spain & $\begin{array}{l}\text { T, P, salinity, nitrates, velocity, } \\
\text { chlorophyll, and turbidity }\end{array}$ & GPRS, ZigBee & Special buoy & Solar & $\begin{array}{l}\text { LabVIEW-based user interface using Google Maps; Solar } \\
\text { energy harvesting; Special buoy; Deployed in a harbor }\end{array}$ \\
\hline Voigt et al. [35] & Sweden; Germany & $\mathrm{T}$, motion, vibration and sound & GPRS & $\begin{array}{l}\text { Simple buoy and } \\
\text { king's buoy }\end{array}$ & No & $\begin{array}{l}\text { Design of an advanced low-cost buoy system; tested in real } \\
\text { environment }\end{array}$ \\
\hline Vesecky et al. [36] & USA & $\mathrm{T}$, wave and location & $900 \mathrm{MHz}$ & Mobile minibuoy & No & $\begin{array}{l}\text { An autonomous mini-buoy prototype (tested in a pool); } \\
\text { GPS is used }\end{array}$ \\
\hline Liu et al. [37] & China & T, Sea depth & ZigBee & Sensor floating & No & $\begin{array}{l}\text { A Perpendicular Intersection (PI) mobile-assisted } \\
\text { localization scheme; deployed in Hong Kong U of S\&T } \\
\text { campus and Tsingtao }\end{array}$ \\
\hline Macias et al. [38] & Spain & $\mathrm{T}$, Visible-field, sound & ZigBee and acoustic & $?$ & $?$ & $\begin{array}{l}\text { Three-tier communication architecture; transmitting video } \\
\text { streaming data; Tested on module of NS-3 }\end{array}$ \\
\hline Roadknight et al. [39] & UK & $\begin{array}{l}\text { T, conductivity, water depth, } \\
\text { turbidity }\end{array}$ & $?$ & Single buoy & No & $\begin{array}{l}\text { A multi-layered scalable and adaptive approach of data } \\
\text { management; deployed off Scroby sands }\end{array}$ \\
\hline Cella et al. [40] & Australia & $\mathrm{T}$, illuminance & ZigBee & $\begin{array}{l}\text { Cylinder waterproof } \\
\text { buoys }\end{array}$ & Solar & $\begin{array}{l}\text { Used underwater wireless communication; deployed in the } \\
\text { Moreton Bay }\end{array}$ \\
\hline Jiang et al. [41] & China & $\mathrm{T}$, velocity and light & ZigBee & Lever buoy & No & $\begin{array}{l}\text { The sleep mechanism and lever buoy; deployed off the } \\
\text { seashore }\end{array}$ \\
\hline Tao et al. [42] & China & Water T, DO and $\mathrm{pH}$ & ZigBee & $\begin{array}{l}\text { Buoys with GPS and } \\
\text { PEA }\end{array}$ & $?$ & $\begin{array}{l}\text { Position determination and location verification using GPS } \\
\text { and PEA (positioning estimation algorithms); tested in two } \\
\text { testbeds }\end{array}$ \\
\hline Alippi et al. [43] & Italy & $\begin{array}{l}\text { Seawater luminosity, } \mathrm{T} \text { and } \\
\text { moisture }\end{array}$ & ZigBee & $\begin{array}{c}\text { Cylinder waterproof } \\
\text { buoys }\end{array}$ & Solar & $\begin{array}{l}\text { Optimal solar energy harvesting; power-aware and } \\
\text { adaptive TDMA protocol; deployed in the Moreton Bay }\end{array}$ \\
\hline De Marziani et al. [44] & Argentina & $\begin{array}{l}\mathrm{T}, \mathrm{P}, \mathrm{PAR} \text { radiation, } \mathrm{pH} \text { and } \\
\text { salinity }\end{array}$ & ZigBee & $\begin{array}{l}\text { Cylinder waterproof } \\
\text { buoys }\end{array}$ & Solar & $\begin{array}{l}\text { A low cost reconfigurable WSN with solar panels; tested in } \\
\text { San Jorge Gulf }\end{array}$ \\
\hline Albaladejo et al. [45] & Spain & $\mathrm{T}, \mathrm{P}$ & ZigBee & Special buoy & Solar & $\begin{array}{l}\text { A new multisensory buoy system with solar panels; } \\
\text { deployed in Mar Menor Lagoon }\end{array}$ \\
\hline Al-Zaidi et al. [46] & UK & $\begin{array}{l}\text { T, depth, wind speed and } \\
\text { direction, humidity, salinity }\end{array}$ & $\begin{array}{l}\text { MADNET routing } \\
\text { protocol }\end{array}$ & Ship & $?$ & $\begin{array}{l}\text { Marine data acquisition and cartography system based on } \\
\text { VHF; hybrid Mobile Ad-hoc/Delay Tolerant routing } \\
\text { protocol (MADNET); tested in North Sea, and English } \\
\text { Channel }\end{array}$ \\
\hline Ferreira et al. [47] & Portugal & $\mathrm{T}$, position & $\begin{array}{c}\text { WiFi, } \\
\text { GPRS/UMTS/LTE, } \\
\text { Acoustic }\end{array}$ & Ship Buoy, ASV & No & $\begin{array}{l}\text { Used autonomous underwater vehicles (AUV), and } \\
\text { autonomous surface vehicles (ASV); tested in Portuguese } \\
\text { coast }\end{array}$ \\
\hline Kaur et al. [48] & India & $\begin{array}{l}\text { Water T, P, wind speed, wind } \\
\text { direction, humidity, cloud } \\
\text { cover, turbidity }\end{array}$ & GPRS & & $?$ & $\begin{array}{l}\text { SentiWordNet is used as an information retrieval tool for } \\
\text { processing messages received from nearby marine areas }\end{array}$ \\
\hline
\end{tabular}


Table 1. Cont.

\begin{tabular}{|c|c|c|c|c|c|c|}
\hline Reference & Country & Sensing Parameters & Comm. Protocols & Buoy & $\begin{array}{c}\text { Energy } \\
\text { Harvesting }\end{array}$ & Key Features (Including Testing and Deployment) \\
\hline Hu et al. [49] & China & T, humility and salinity & $?$ & AUV & $?$ & $\begin{array}{l}\text { Ring Broadcast Mechanism is used to guide searching } \\
\text { direction of sensor nodes; providing self-adaptive dynamic } \\
\text { routing mechanism to search the alternative path }\end{array}$ \\
\hline Mourya et al. [50] & UK & T, P, salinity, oxygen level & Acoustic & $\begin{array}{l}\text { Anchors with } \\
\text { acoustic modems }\end{array}$ & Solar & $\begin{array}{l}\text { A framework for spatio-temporal monitoring of } \\
\text { underwater acoustic sensor networks; anchors are } \\
\text { deployed in the ROI inspired by compressive sensing }\end{array}$ \\
\hline Morozs et al. [51] & UK & $\begin{array}{l}\text { T, P, humidity, optical, distance, } \\
\text { sound, magnetic field, motion }\end{array}$ & Acoustic & $\begin{array}{l}\text { Autonomous surface } \\
\text { vehicle (ASV) }\end{array}$ & No & $\begin{array}{l}\text { Implementation of the TDA-MAC protocol in practice, and } \\
\text { practical issues prompted several crucial modifications to } \\
\text { the TDA-MAC protocol }\end{array}$ \\
\hline Song et al. [52] & China & Water T, P, salinity and $\mathrm{PH}$ & Acoustic & Buoy & $?$ & $\begin{array}{l}\text { Underwater positioning algorithm of electing anchor } \\
\text { nodes and the self-repairing localization algorithm based } \\
\text { on anchor nodes failure }\end{array}$ \\
\hline \multicolumn{7}{|c|}{ Application Area: Water Quality Monitoring } \\
\hline Yang et al. [53] & USA & $\mathrm{pH}$ & RF and acoustic & PVC housing & No & $\begin{array}{l}\text { Various interface circuits; } 5 \text { air-based sensor nodes; lab } \\
\text { testing only }\end{array}$ \\
\hline Seders et al. [54] & USA & $\mathrm{T}, \mathrm{pH}$, and $\mathrm{DO}$ & $433 \mathrm{MHz}$ & $\begin{array}{l}\text { Box and polyethylene } \\
\text { ring }\end{array}$ & No & $\begin{array}{l}\text { A LakeNet sensor pod and an altered sampling strategy; } \\
\text { tested a prototype in a small lake }\end{array}$ \\
\hline Regan et al. [55] & Ireland & $\begin{array}{l}\mathrm{T}, \mathrm{pH}, \text { turbidity, } \mathrm{DO} \text { and } \\
\text { conductivity }\end{array}$ & ZigBee & Inshore sensor buoys & Solar & $\begin{array}{l}\text { A real-time heterogeneous water quality monitoring; } \\
\text { deployed in five sites on the River Lee, Ireland }\end{array}$ \\
\hline O'Connor et al. [56] & Ireland & $\mathrm{T}$, conductivity and depth & $?$ & Buoys & $?$ & $\begin{array}{l}\text { A multi-modal environment monitoring network based on } \\
\text { WSN and visual image; tested in River Lee, Poolbeg } \\
\text { Marina and Galway Bay }\end{array}$ \\
\hline Hadjimitsis et al. [57] & Cyprus & $\mathrm{T}, \mathrm{P}$, salinity and turbidity & GPRS & $\begin{array}{l}\text { Cylinder waterproof } \\
\text { buoy }\end{array}$ & No & $\begin{array}{l}\text { Integrated satellite remote sensing and WSN; deployed in } \\
\text { a beach }\end{array}$ \\
\hline Jin et al. [58] & China & $\mathrm{T}, \mathrm{pH}, \mathrm{DO}$, and salinity & ZigBee GPRS & $?$ & No & An early WSN-based water monitoring system \\
\hline Alkandari et al. [59] & Kuwait & Water $\mathrm{T}, \mathrm{DO}$, and $\mathrm{pH}$ & $\begin{array}{l}\text { ZigBee } 802.11 \\
\text { Ethernet radio }\end{array}$ & $?$ & Solar & $\begin{array}{l}\text { Used ZigBee and } 802.11 \text { and a high capacity solar panel; } \\
\text { tested in a pool }\end{array}$ \\
\hline Adamo et al. [60] & Italy & $\begin{array}{l}\text { T, salinity, conductivity, } \\
\text { turbidity and chlorophyll-a }\end{array}$ & GPRS & Self-sufficient buoy & $?$ & $\begin{array}{l}\text { Two different probe solutions for field covering; tested in } \\
\text { Apulia region }\end{array}$ \\
\hline \multicolumn{7}{|c|}{ Application Area: Coral Reefs Monitoring } \\
\hline Bromage et al. [61] & USA & $\begin{array}{l}\text { T, } \mathrm{P}, \mathrm{pH} \text {, light, and } \\
\text { conductivity }\end{array}$ & $900 \mathrm{MHz}$ & Watertight housing & No & Deployed in Monterey Bay \\
\hline Berlian et al. [62] & Indonesia & $\begin{array}{c}\text { T, ORP, } \mathrm{pH}, \text { Electrical } \\
\text { Conductivity, DO, audio/video }\end{array}$ & $?$ & $\begin{array}{l}\text { Remotely Operated } \\
\text { Vehicle, buoy }\end{array}$ & No & $\begin{array}{l}\text { Remotely Operated Vehicles with water quality sensors; } \\
\text { Big Data analysis }\end{array}$ \\
\hline
\end{tabular}


Table 1. Cont

\begin{tabular}{|c|c|c|c|c|c|c|}
\hline Reference & Country & Sensing Parameters & Comm. Protocols & Buoy & $\begin{array}{c}\text { Energy } \\
\text { Harvesting }\end{array}$ & Key Features (Including Testing and Deployment) \\
\hline \multicolumn{7}{|c|}{ Application Area: Fish Farm Monitoring } \\
\hline López et al. [63] & Spain & $\mathrm{T}$ and $\mathrm{pH}$ & ZigBee & $?$ & No & $\begin{array}{l}\text { A sub-layer-based power consumption algorithm; tested in } \\
\text { a pool }\end{array}$ \\
\hline Yang et al. [64] & China & $\begin{array}{l}\text { Water T, } \mathrm{pH} \text { value, salinity, DO } \\
\text { and COD }\end{array}$ & GPRS & $?$ & Solar & $\begin{array}{l}\text { Multi-hop communication protocol, multiple nodes, and } \\
\text { SMT; tested in an aquatic experimental base }\end{array}$ \\
\hline Leblond et al. [65] & France & $\begin{array}{l}\text { T, depth, salinity, position, } \\
\text { catches }\end{array}$ & GPRS & Vessels & No & $\begin{array}{l}\text { Fixed on fishing gears, self-powered, autonomous; tested } \\
\text { in Bay of Biscay }\end{array}$ \\
\hline Lloret et al. [66] & Spain & Sediment depositions & Acoustic & Bouy & $?$ & Ultrasonic sensor; tested through simulations \\
\hline Meera et al. [67] & India & $\begin{array}{l}\text { Sea surface } \mathrm{T} \text {, quality of sea } \\
\text { water, } \mathrm{pH} \text {, chlorophyll }\end{array}$ & WiFi & Fishing vessels & No & $\begin{array}{l}\text { A multi-level P2MP infrastructure network- OceanNet, } \\
\text { protocol performance comparison of CoAP, AMQP and } \\
\text { MQTT }\end{array}$ \\
\hline Lloret et al. [68] & Spain & Amount of pollution & $?$ & Buoy & $?$ & $\begin{array}{l}\text { A group-based underwater WSN for monitoring fecal } \\
\text { waste and uneaten feed; tested on OPNET Modeler } \\
\text { network simulator }\end{array}$ \\
\hline \multicolumn{7}{|c|}{ Application Area: Wave and current monitoring } \\
\hline Marimon et al. [69] & Philippines & Acceleration, angle & $\begin{array}{c}\text { ZigBee, } \\
\text { GSM/GPRS/EDGE }\end{array}$ & Buoy & Solar & $\begin{array}{l}\text { Integrated different wave sensors; threshold values } \\
\text { generated based on statistics; tested in Manila Bay }\end{array}$ \\
\hline Chen et al. [70] & China & Current velocities & $?$ & $?$ & No & $\begin{array}{l}\text { A temporal evolution model to describe the ocean current } \\
\text { process based on the temporal correlation of the current } \\
\text { velocity. }\end{array}$ \\
\hline
\end{tabular}

Notes: “T”: Temperature; “P”: Pressure; “DO”: Dissolved Oxygen; “COD”: Chemical Oxygen Demand; “No" under Energy Harvesting: Battery power is used; "?": Related information is not available from the source. 
From this long list of systems, we can see that most of the efforts are related to general ocean sensing and monitoring [34-44,46-48] and water quality monitoring [53-60,62]. Some specific efforts have been made for fish farm monitoring [63,65,66,68], coral reef monitoring [61,62], wave and current monitoring [69], and marine shellfish monitoring [64]. Several projects focus on specific technologies or devices, e.g., buoys $[35,36,44,45,47,64]$, energy saving and harvesting $[34,40,43-45,55,59,63,64]$, routing protocols [46,64], data transmitting approaches [38,46,47], and data analysis [62].

It can also be found that testing places are different among these systems. About half of the developed systems have been tested or deployed in real marine or river environments $[34,35$, 37,39-41,44-47,55-57,60,61,65,69]; a number of them were experimented in lab settings or indoor environments [38,53,64,68]; some were tested in outdoor pools or small ponds/lakes [36,54,59,63]; and several of them were only tested through simulations $[38,66,68]$.

It is very interesting to note that most projects, systems, and applications have been developed by research groups in a small number of countries, including China [37,41,42,58,64], USA [36,53,54,61], Spain [38,45,63,68], UK [46], Indonesia [62], Philippines [69], India [48], Portugal [47], France [65], and Ireland $[55,56]$. In these completed systems, most of them occurred on water surfaces $[34,35,37,39$ $46,48,54-65,68,69]$ and only a few of them were deployed under water $[38,47,53,66]$. Please note that underwater wireless sensor network is not the focus of this paper and we will briefly discuss this later in the paper.

Even though many researchers discussed different options for energy harvesting including solar, wind, waves, and ocean currents, only solar energy has been used in about a third of these systems and applications.

While most systems use GPRS and/or ZigBee for wireless communications, a few systems use underwater acoustic communication $[38,47,53,66]$.

Offshore and deep-sea fish farming has been emerging, which provides more opportunities and also challenges, not only for marine environment monitoring but also for operation controls and marine environment protection.

\section{New Technologies for Marine Environment Monitoring and Protection}

\subsection{Data Analysis}

Recent fast development and deployment of IoT technologies in marine environment monitoring created huge amounts of data, while the recent advancement of Big Data analytics facilitated the analysis of these marine environment data.

As in many other IoT-based data collection systems, dealing with marine environment data also faces some major challenges, particularly the large amount of data and significant bad data. Researchers around the word have been trying to address these challenges. Yang et al. [71] proposed a method to quickly describe the contour of data collected over the Internet of Things (IoT). The distribution of contour lines can be calculated accurately in a short time.

Blix and Eltoft [72] proposed an automatic model selection algorithm (AMSA) to determine the best model for a given matchup dataset. It can automatically choose between regression models to estimate the parameter of interest. It also finds out the number and combination of features to be used for obtaining the best model. They used four Machine Learning feature ranking methods and three Machine Learning regression models to estimate oceanic chlorophyll-a in the global and optically complex waters.

Zhong et al. [73] developed a fast fuzzy C-means clustering algorithm to analyze water environment monitoring data of the Three Gorges Reservoir Area. The hard cluster center can be treated as the initial value of the fuzzy cluster center to accelerate the speed of convergence and reduce the number of iterations.

Addison et al. [74] summarized the challenges in marine environment data management and interpretation caused by the implications of Big Data. They suggested a solution for the management 
of Big Data, which requires new collaborations between marine practitioners and data scientists with expertise in programming languages and packages like $\mathrm{R}$ and Python.

Belghith et al. [75] proposed a deep learning-based approach in a marine Big Data setting that enables to classify these diverse acoustic sounds not only considering marine mammals signals.

$\mathrm{Li}$ et al. [76] presented a support vector regression architecture with smoothness priority for marine sensor data prediction to handle the abruptly fluctuating, multi-noise, non-stationary and abnormal data. The smoother plays the role of preprocessing to handle the outliers and noises in marine sensor data, providing stable initialization values for the next nonlinear approximation based on support vector machines.

Since the existing current correlation analysis method for ocean monitoring big data is time consuming and stability is poor, Song et al. [77] developed a new method by sending the collected data to the cloud storage system. Based on the global and local Moran index calculations, the ocean big data of relatively high correlation were saved to the adjacent data center, which reduces the ocean monitoring data correlation analysis time.

Radeta et al. [78] developed a low-cost passive acoustic monitoring (PAM) system for nautical citizen science and real-time acoustic augmentation of whale-watching experiences. This paper used machine learning identify vocal acoustic samples of common cetaceans like whales and dolphins with acoustic features (clicks, moans or whistles).

It is clear that research and development efforts on the application of Big Data analytics in marine environment monitoring have been growing recently.

\subsection{Network Topology Control}

In wireless sensor networks (WSNs), network topology control capability is a key factor in the performance of the entire network. A reasonable WSN topology control structure can effectively improve the efficiency of network communication protocols and the overall performance of the network. A good network topology helps extend the overall life cycle of the network. Therefore, WSN topology control optimization technology is the key to determining the overall performance of the network, including the network coverage and connectivity. The node selection policy changes the state of the node itself and avoids the communication link redundancy among nodes to form a performance-optimized network structure. Table 2 summarizes the advantages and disadvantages of different topology control algorithms for underwater wireless senor networks (UWSNs) [79]. 
Table 2. Classification of Topology Control Algorithms for underwater wireless senor networks (UWSNs).

\begin{tabular}{|c|c|c|c|}
\hline Category & Main Idea & Advantages & Disadvantages \\
\hline Power control based & $\begin{array}{l}\text { The proper transmission } \\
\text { power level is assigned } \\
\text { to each node to } \\
\text { guarantee enough signal } \\
\text { strength at the receiver } \\
\text { that it can successfully } \\
\text { receive and decode the } \\
\text { transmitted message }\end{array}$ & $\begin{array}{l}\text { Simple; scalable; } \\
\text { conserves energy; does } \\
\text { not change the sensing } \\
\text { coverage; can overcome } \\
\text { time-varying acoustic } \\
\text { channel quality. }\end{array}$ & $\begin{array}{l}\text { May diminish the } \\
\text { network connectivity; } \\
\text { increases the number of } \\
\text { hops and end-to-end } \\
\text { delay. }\end{array}$ \\
\hline $\begin{array}{l}\text { Wireless interface mode } \\
\text { management based }\end{array}$ & $\begin{array}{l}\text { The wireless interface of } \\
\text { nodes alternates between } \\
\text { active, sleeping, and } \\
\text { powered-off modes. This } \\
\text { change reduces the } \\
\text { amount of unnecessary } \\
\text { time a node spends } \\
\text { listening to the channel. }\end{array}$ & $\begin{array}{l}\text { Simple; scalable; } \\
\text { conserves energy relative } \\
\text { channel polling; does not } \\
\text { change sensing coverage. }\end{array}$ & $\begin{array}{l}\text { Changes network } \\
\text { density; changes routing } \\
\text { paths from time to time; } \\
\text { increases delay. }\end{array}$ \\
\hline Mobility assisted based & $\begin{array}{l}\text { Some mobile nodes are } \\
\text { moved to new locations } \\
\text { in different depths or } \\
\text { with a predetermined } \\
\text { trajectory, creating new } \\
\text { interconnections. }\end{array}$ & $\begin{array}{l}\text { Improves network } \\
\text { connectivity; deals with } \\
\text { network partitions; } \\
\text { improves data collection } \\
\text { from hop spots. }\end{array}$ & $\begin{array}{l}\text { Needs trajectory } \\
\text { planning procedures; } \\
\text { increases energy cost for } \\
\text { mobility; may change } \\
\text { sensing coverage. }\end{array}$ \\
\hline
\end{tabular}

Even though this classification of topology control algorithms is for underwater wireless sensor networks, it can be well applied to the IoT-based marine environment monitoring in general. Please note that UWSN is not the focus of this paper. For comprehensive reviews of underwater sensor networks and applications, please refer to references [80,81]. It is also interesting to check out the concept of Internet of Underwater Things (IoUT) and its potential applications [82].

The rest of this section provides a review of some examples of interesting approaches proposed and developed in the literature on network topology control. Kim et al. [83] used power control to achieve reliable data delivery based on the sea surface movement that affects the surface signal reflection and the strength of the received signal at a node. Bai et al. [84] proposed an approach to reduce link interference and achieved high throughput by using a correlation matrix to describe the source-destination relationship and conflict relationships among the links. Power control is used to achieve a Signal to Noise Ratio (SNR) larger than the decoding threshold.

Su et al. [85] proposed a cycle difference set-based protocol to determine the number and positions of active and sleep intervals in one cycle to guarantee that both the transmitter and receiver are awake for communication. Coutinho et al. [86] developed an optimization model to investigate the performance of the on-the-fly adjustment of the sleep interval in duty-cycled UWSNs to achieve a balanced energy consumption.

Khan et al. [87] presented a method to incorporate the AUV resurfacing time in the VoI function and AUV path planning algorithm. Coutinho et al. [88] designed the distributed topology control (DTC) and centralized topology control (CTC) depth adjustment-based topology control algorithms for disconnected and void nodes repositioning to improve network connectivity and data routing.

\subsection{New Communication Routing Protocols}

With the advancement of communication technologies, new communication routing protocols have been proposed and developed for marine environment monitoring systems. Faheem et al. [89] proposed a chromosome (routing path), which consists of sequences of non-negativity integers that denote the IDs of genes ( $\mathrm{CH}$ nodes) through which a routing path passes. In a routing path, the 
order of each $\mathrm{CH}$ is represented by the locus of chromosome in which the gene of the first locus is always reserved for the source $\mathrm{CH}$ nodes. A looping feature of selection $(\phi \mathrm{s})$, crossover $(\phi c)$, and mutation $(\phi \mathrm{m})$ operators is applied on each individual to improve the quality of the solution through the pre-defined probabilities $(\phi p)$ until the termination criterion is satisfied. The probability of the mutation rate increases from an extremely low value of 0.01 to its maximum value of 0.05 . Highly stable small clustering mechanism is used to organize sensor nodes into a connected hierarchy for distributing energy and data traffic load evenly in the network.

The protocol proposed by Javaid et al. [90] is called balanced energy adaptive routing (BEAR). It exploits the location information, selects the neighbors, chooses the facilitating and successor nodes based on cost function value, and finally selects the forwarder node that has residual energy more than the average residual energy of the network. BEAR allows nodes to communicate directly with the sink node leading to an increase in the number of packets being dropped.

Alageswaran and Swapna [91] proposed an enhanced duty cycled multiple rendezvous multichannel media access control (DMM-MAC) for handling more volume of data in multi-hop underwater wireless sensor networks (UWSNs) for marine eco systems. This protocol distributes bursty sensor data by dynamically tuning the duty cycles, and hence network performance is enhanced dramatically. It is equipped with one modem and the propagation delays or relative distances need not to be known by the other nodes in the network. Less energy is consumed, and it is easy to forward the data based on priority. One cycle consists of several frames and is subdivided into an active section and a sleep section. Each node can use the other time slot when the time slot is free.

\section{Major Challenges and Opportunities}

\subsection{Energy Management}

Because marine environment monitoring and protection systems work on hash environments as mentioned above, battery replacement is difficult and costly. It is therefore very important to have an efficient energy management system together and preferably with an energy harvesting capability.

Typical energy options for sensor nodes include batteries, capacitors, fuel cells, and energy harvesting. A battery is widely used in sensor nodes, and in fact in over half of the systems reviewed under this paper. However, using batteries in sensor nodes has a number of issues [92] including the replacement difficulty, risk of losing power during operation, and environment contamination. It is therefore important to explore alternative power supply options for sensor nodes. Energy harvesting is a natural way to go. In marine environments, energy harvesting options including solar, wind, water waves, and currents. The most outstanding energy harvesting at the moment is photovoltaics (solar energy) [92].

Usually, network energy consumption is increasing at a very high rate due to an increase in data rates, increase in the number of Internet-enabled services and rapid growth of Internet connected edge-devices [21]. The drastic increase in IoT devices requires efficient fabrication of batteries because of the uncertainty in battery dissipation. On the other hand, the devices in marine environment monitoring and protection systems are heterogeneous in nature, each with various capabilities and numerous requirements [93]. Hence, the requirement of cost effective and energy efficient routing strategy in terms of space and time arises in future wireless communication networks.

\subsection{Standardization}

With the wider scope of marine environment monitoring and protection, international cooperation projects are emerging one after another. According to the interests of the projects, various application platforms and methods have their own characteristics and cannot be compatible with each other. Even though a number of networking protocols and standards for Internet of Things have been proposed and developed [94,95], they are not sufficient for applications in marine environment monitoring. In addition to the standards of IoT networking, it is also important to provide the industry with standards 
for IoT devices, equipment, and platforms for marine environment monitoring and protection applications, and providing different levels of governments and marine environment management agencies with standards for marine environment data management, analysis, and reporting. As a result, the standardization of platform development for marine environment monitoring and protection systems brings challenges, including:

1. Standardization of IoT devices specifically for marine environment monitoring and protection, including sensor and actuator nodes, routers and gateways.

2. Standardization of IoT platforms and system technologies for marine environment monitoring and protection, including communication network structures, protocols, and algorithms.

3. Standardization of computing and data storage technologies for marine environment monitoring and protection, including cloud, fog, and edge computing mechanisms, data archiving and warehousing techniques.

4. Standardization of data analysis outputs and reporting formats for exchange among different organizations and governments.

\subsection{Marine Environment Protection}

Currently, the environmental protection issue is one of the most important issues around the world. The ultimate goal of monitoring the ocean is to protect the marine environment. Most of the current marine environment monitoring applications collected and analyzed massive data from the ocean, but there is no action on protection controls yet. With the advancement and sophistication of IoT and Big Data technologies and their wide applications in marine environment monitoring and protection, we are confident that active marine environment protection measures, technologies, and systems will be developed and deployed in the near future. Massive data collected from marine environments will be analyzed using advanced Big Data analytics and the results will be sent to the related marine environment management agencies/control centers for quick decision making and real time manual interventions in order to protect the marine environment from some disasters (e.g., oil spills and bad weather). On the other hand, some autonomous vessels or other devices (actuators) can also automatically and quickly react to disasters and other events in order to protect the marine environment. In the case of a fishing farm application, data collected from the fish farm environment can be analyzed and used to provide the best fish growth condition and the best feeding.

\section{Conclusions}

During the past couple of decades, marine environment monitoring has attracted wide attention. Governments and research organizations have heavily invested in the research and development of new technologies in this area. Advanced information and communication technologies have been applied to the development of various marine environment monitoring technologies and systems. Internet of Things has played an important role in this area. This paper presents an updated review of the related technologies and systems on the application of the Internet of Things in marine environment monitoring.

A comprehensive review of about 40 related projects revealed that most systems and applications developed thus far are for ocean sensing and monitoring and water quality monitoring. Some specific efforts have been made for fish farm monitoring, coral reef monitoring, wave and current monitoring. Several projects focused on specific technologies or devices like buoys, energy saving and harvesting devices, routing protocols, data transmitting mechanisms, and data analysis techniques.

It can also be noted that testing places are very much different among these projects. About half of the developed systems have been tested or deployed in real marine or river environments; a number of them were experimented in lab settings or indoor environments; a few others were tested in outdoor pools or small ponds and lakes; and several of them were only tested through simulations. 
While most systems use GPRS and/or ZigBee for wireless communication, a few systems used underwater acoustic communication.

Emerging offshore and deep-sea fish farming provides more opportunities and also challenges, not only for marine environment monitoring but also for operation controls and marine environment protection, which is a new area of research.

The energy management issue is mainly considered from two aspects: Reducing energy consumption and using alternative renewable energy sources. Optimizing network topologies and developing advanced routing protocols are the ways to reduce energy consumption. Even though many researchers discussed different options for energy harvesting including solar, wind, waves and ocean currents as alternative renewable energy sources, only solar energy has been used in about a third of the developed systems.

The results of Big Data analytics can be used not only for feedback to marine environment management agencies and control centers for quick decision making and real time manual interventions but also for autonomous vessels and remotely deployed devices to take real time actions in order to protect the marine environment from some disasters (e.g., oil spills and bad weather). It is a growing area of research and development.

This review also identified several research challenges and opportunities, including energy management, standardization of system platforms and technologies, and marine environment protection measures.

Author Contributions: All the co-authors have contributed to the conceptualization of the paper and the review of the cited references. As the first author, G.X. prepared the first draft based on his previously published survey paper. X.S. searched and collected the most recent references and provided a first review of these references. Y.S. contributed to the review of new IoT and wireless communication technologies. W.S. defined the paper structure, re-organized the content, and edited the whole paper.

Funding: This work was supported in part by the Science Foundation for Enhancing School with Innovation of Guangdong Ocean University (Grant Nos. GDOU2015050207).

Conflicts of Interest: No conflict of interests exits in the submission of this manuscript, and the manuscript has been approved by all the co-authors for publication. We would also like to declare that the work described in this paper is original and it has not been published previously, and not under consideration for publication elsewhere, in whole or in part.

\section{References}

1. Van Kranenburg, R. The Internet of Things: A Critique of Ambient Technology and the All-Seeing Network of Rfid; Institute of Network Cultures: Amsterdam, The Netherlands, 2008.

2. Yang, C.; Shen, W.; Wang, X. Internet of Things in manufacturing: An overview. IEEE SMC Mag. 2018, 4, 6-15.

3. Cook, D.J.; Crandall, A.S.; Thomas, B.L.; Krishnan, N.C. Casas: A smart home in a box. Computer 2013, 46, 62-69. [CrossRef]

4. Finch, E. Is ip everywhere the way ahead for building automation? Facilities 2001, 19, 396-403. [CrossRef]

5. Komninos, N.; Philippou, E.; Pitsillides, A. Survey in smart grid and smart home security: Issues, challenges and countermeasures. IEEE Commun. Surv. Tutor. 2014, 16, 1933-1954. [CrossRef]

6. Talcott, C. Cyber-physical systems and events. In Software-Intensive Systems and New Computing Paradigms; Springer: Berlin/Heidelberg, Germany, 2008; pp. 101-115.

7. Yongfu, L.; Dihua, S.; Weining, L.; Xuebo, Z. A service-oriented architecture for the transportation cyber-physical systems. In Proceedings of the 31st Control Conference (CCC), Hefei, China, 25-27 July 2012; pp. 7674-7678.

8. Ungurean, I.; Gaitan, N.-C.; Gaitan, V.G. An IoT architecture for things from industrial environment. In Proceedings of the 10th International Conference on Communications (COMM), Bucharest, Romania, 29-31 May 2014; pp. 1-4.

9. Wang, C.; Bi, Z.; Da Xu, L. IoT and cloud computing in automation of assembly modeling systems. IEEE Trans. Ind. Inform. 2014, 10, 1426-1434. [CrossRef] 
10. Catarinucci, L.; De Donno, D.; Mainetti, L.; Palano, L.; Patrono, L.; Stefanizzi, M.L.; Tarricone, L. An IoT-aware architecture for smart healthcare systems. IEEE Internet Things J. 2015, 2, 515-526. [CrossRef]

11. Yan, Y.; Qian, Y.; Sharif, H.; Tipper, D. A survey on smart grid communication infrastructures: Motivations, requirements and challenges. IEEE Commun. Surv. Tutor. 2013, 15, 5-20. [CrossRef]

12. Dameri, R.P.; Rosenthal-Sabroux, C. Smart City: How to Create Public and Economic Value with High Technology in Urban Space; Springer: Cham, Switzerland, 2014.

13. Boonma, P.; Suzuki, J. An adaptive, scalable and self-healing sensor network architecture for autonomous coastal environmental monitoring. In Proceedings of the IEEE Conference on Technologies for Homeland Security, Woburn, MA, USA, 16-17 May 2007; p. 18.

14. Hadim, S.; Mohamed, N. Middleware: Middleware challenges and approaches for wireless sensor networks. IEEE Distrib. Syst. Online 2006, 7, 1. [CrossRef]

15. Albaladejo, C.; Sánchez, P.; Iborra, A.; Soto, F.; López, J.A.; Torres, R. Wireless sensor networks for oceanographic monitoring: A systematic review. Sensors 2010, 10, 6948-6968. [CrossRef]

16. Alippi, C.; Camplani, R.; Galperti, C.; Roveri, M. Effective design of wsns: From the lab to the real world. In Proceedings of the 2008 3rd International Conference on Sensing Technology (ICST), Tainan, Taiwan, 30 November-3 December 2008; pp. 1-9.

17. Cardei, M.; Wu, J. Energy-efficient coverage problems in wireless ad-hoc sensor networks. Comput. Commun. 2006, 29, 413-420. [CrossRef]

18. Xu, G.; Shen, W.; Wang, X. Applications of wireless sensor networks in marine environment monitoring: A survey. Sensors 2014, 14, 16932-16954. [CrossRef]

19. Zhang, X. Application of Internet of Things technology in agricultural production. In Proceedings of the 2018 the International Symposium on Big Data and Artificial Intelligence, Hong Kong, China, 29-30 December 2018; pp. 269-274.

20. Antão, L.; Pinto, R.; Reis, J.; Gonçalves, G. Requirements for testing and validating the industrial Internet of Things. In Proceedings of the 2018 IEEE International Conference on Software Testing, Verification and Validation Workshops (ICSTW), Vasteras, Sweden, 9-13 April 2018; pp. 110-115.

21. Khan, R.; Khan, S.U.; Zaheer, R.; Khan, S. Future Internet: The Internet of Things architecture, possible applications and key challenges. In Proceedings of the 2012 10th International Conference on Frontiers of Information Technology (FIT), Islamabad, India, 17-19 December 2012; pp. 257-260.

22. Yang, Z.; Yue, Y.; Yang, Y.; Peng, Y.; Wang, X.; Liu, W. Study and application on the architecture and key technologies for IoT. In Proceedings of the 2011 International Conference on Multimedia Technology (ICMT), Hangzhou, China, 26-28 July 2011; pp. 747-751.

23. Wu, M.; Lu, T.-J.; Ling, F.-Y.; Sun, J.; Du, H.-Y. Research on the architecture of Internet of Things. In Proceedings of the 2010 3rd International Conference on Advanced Computer Theory and Engineering (ICACTE), Chengdu, China, 20-22 August 2010; pp. V5:484-V485:487.

24. Li, M.; Yang, B. A survey on topology issues in wireless sensor network. In Proceedings of the 2006 International Conference on Wireless Networks (ICWN), Las Vegas, NV, USA, 26-29 June 2006; p. 503.

25. Zeng, Y.; Sreenan, C.J.; Xiong, N.; Yang, L.T.; Park, J.H. Connectivity and coverage maintenance in wireless sensor networks. J. Supercomput. 2010, 52, 23-46. [CrossRef]

26. Flammini, A.; Ferrari, P.; Marioli, D.; Sisinni, E.; Taroni, A. Wired and wireless sensor networks for industrial applications. Microelectron. J. 2009, 40, 1322-1336. [CrossRef]

27. Kim, S.-Y.; Guzide, O.; Cook, S. Towards an optimal network topology in wireless sensor networks: A hybrid approach. In Proceedings of the ISCA First International Conference on Sensor Networks and Applications, San Francisco, CA, USA, 4-6 November 2009.

28. Anastasi, G.; Conti, M.; Di Francesco, M.; Passarella, A. Energy conservation in wireless sensor networks: A survey. Ad Hoc Netw. 2009, 7, 537-568. [CrossRef]

29. Porter, J.; Arzberger, P.; Braun, H.-W.; Bryant, P.; Gage, S.; Hansen, T.; Hanson, P.; Lin, C.-C.; Lin, F.-P.; Kratz, T. Wireless sensor networks for ecology. AIBS Bull. 2005, 55, 561-572. [CrossRef]

30. Jiang, Z. User density in a cluster underwater acoustic network. Int. J. Intell. Control Syst. 2012, 17, 31-40.

31. Jiang, Z. Underwater acoustic networks-issues and solutions. Int. J. Intell. Control Syst. 2008, 13, $152-161$.

32. Zhu, Y.; Peng, Z.; Cui, J.-H.; Chen, H. Toward practical mac design for underwater acoustic networks. IEEE Trans. Mobile Comput. 2015, 14, 872-886. [CrossRef] 
33. Zixuan, Y.; Zhifang, W.; Chang, L. Research on marine environmental monitoring system based on the Internet of Things technology. In Proceedings of the IEEE International Conference on Electronic Information and Communication Technology (ICEICT), Harbin, China, 20-22 August 2016; pp. 121-125.

34. Pérez, C.A.; Jimenez, M.; Soto, F.; Torres, R.; López, J.; Iborra, A. A system for monitoring marine environments based on wireless sensor networks. In Proceedings of the OCEANS 2011 IEEE-Spain, Santander, Spain, 6-9 June 2011; pp. 1-6.

35. Voigt, T.; Osterlind, F.; Finne, N.; Tsiftes, N.; He, Z.; Eriksson, J.; Dunkels, A.; Bamstedt, U.; Schiller, J.; Hjort, K. Sensor networking in aquatic environments-experiences and new challenges. In Proceedings of the 32nd IEEE Conference on Local Computer Networks, Dublin, Ireland, 15-18 October 2007; pp. 793-798.

36. Vesecky, J.F.; Laws, K.; Petersen, S.I.; Bazeghi, C.; Wiberg, D. Prototype autonomous mini-buoy for use in a wireless networked, ocean surface sensor array. In Proceedings of the 2007 IEEE Conference on Geoscience and Remote Sensing Symposium (IGARSS), Barcelona, Spain, 23-27 July 2007; pp. 4987-4990.

37. Liu, K.; Yang, Z.; Li, M.; Guo, Z.; Guo, Y.; Hong, F.; Yang, X.; He, Y.; Feng, Y.; Liu, Y. Oceansense: Monitoring the sea with wireless sensor networks. ACM SIGMOBILE Mobile Comput. Commun. Rev. 2010, 14, 7-9. [CrossRef]

38. Macias, E.; Suarez, A.; Chiti, F.; Sacco, A.; Fantacci, R. A hierarchical communication architecture for oceanic surveillance applications. Sensors 2011, 11, 11343-11356. [CrossRef]

39. Roadknight, C.; Parrott, L.; Boyd, N.; Marshall, I.W. A layered approach to in situ data management on a wireless sensor network. In Proceedings of the 2004 Intelligent Sensors, Sensor Networks and Information Processing Conference, Melbourne, VIC, Australia, 14-17 December 2004; pp. 85-90.

40. Cella, U.M.; Shuley, N.; Johnstone, R. Wireless sensor networks in coastal marine environments: A study case outcome. In Proceedings of the Fourth ACM International Workshop on UnderWater Networks, Berkeley, CA, USA, 3 November 2009; p. 8.

41. Jiang, M.; Guo, Z.; Hong, F.; Ma, Y.; Luo, H. Oceansense: A practical wireless sensor network on the surface of the sea. In Proceedings of the IEEE International Conference on Pervasive Computing and Communications(PerCom), Galveston, TX, USA, 9-13 March 2009; pp. 1-5.

42. Tao, C.; Hanfei, Z.; Ming, C.; Guofu, F. Implementation study of a home position monitoring system for marine environment. In Proceedings of the 2010 2nd IEEE International Conference on Information Management and Engineering (ICIME), Chengdu, China, 16-18 April 2010; pp. 224-231.

43. Alippi, C.; Camplani, R.; Galperti, C.; Roveri, M. A robust, adaptive, solar-powered wsn framework for aquatic environmental monitoring. IEEE Sens. J. 2011, 11, 45-55. [CrossRef]

44. De Marziani, C.; Alcoleas, R.; Colombo, F.; Costa, N.; Pujana, F.; Colombo, A.; Aparicio, J.; Alvarez, F.; Jimenez, A.; Urena, J. A low cost reconfigurable sensor network for coastal monitoring. In Proceedings of the OCEANS 2011 IEEE-Spain, Santander, Spain, 6-9 June 2011; pp. 1-6.

45. Albaladejo, C.; Soto, F.; Torres, R.; Sánchez, P.; López, J.A. A low-cost sensor buoy system for monitoring shallow marine environments. Sensors 2012, 12, 9613-9634. [CrossRef]

46. Al-Zaidi, R.; Woods, J.C.; Al-Khalidi, M.; Hu, H. Building novel vhf-based wireless sensor networks for the Internet of Marine Things. IEEE Sens. J. 2018, 18, 2131-2144. [CrossRef]

47. Ferreira, H.; Silva, F.; Sousa, P.; Matias, B.; Faria, A.; Oliveira, J.; Almeida, J.M.; Martins, A.; Silva, E. Autonomous systems in remote areas of the ocean using bluecom+ communication network. In Proceedings of the OCEANS-Anchorage, Anchorage, AK, USA, 18-21 September 2017; pp. 1-6.

48. Kaur, S.; Jain, S.; Virmani, D. Deployment of wireless sensor networks for intelligent information retrieval in marine environment. In Proceedings of the 2015 IEEE International Conference on Control System, Computing and Engineering (ICCSCE), George Town, Malaysia, 27-29 November 2015; pp. 371-376.

49. Hu, Y.; Zheng, Y.; Liu, H. A route maintenance method for marine mobile sensor network based on ring broadcast mechanism. In Proceedings of the 2018 18th IEEE International Conference on Communication Technology (ICCT), Chongqing, China, 8-11 October 2018; Institute of Electrical and Electronics Engineers Inc.: Chongqing, China, 2018; pp. 533-537.

50. Mourya, R.; Saafin, W.; Dragone, M.; Petillot, Y. Ocean monitoring framework based on compressive sensing using acoustic sensor networks. In Proceedings of the OCEANS 2018 MTS/IEEE Charleston, Charleston, SC, USA, 22-25 October 2018; Institute of Electrical and Electronics Engineers Inc.: Charleston, SC, USA, 2018. 
51. Morozs, N.; Mitchell, P.D.; Zakharov, Y.; Sherlock, B.; Neasham, J.A.; Tsimenidis, C.C.; Mourya, R.; Petillot, Y.R.; Gibney, T.; Dragone, M.; et al. Robust tda-mac for practical underwater sensor network deployment: Lessons from usmart sea trials. In Proceedings of the 13th ACM International Conference on Underwater Networks and Systems, WUWNet 2018, Shenzhen, China, 3-5 December 2018; Association for Computing Machinery: Shenzhen, China, 2018.

52. Song, Y.; Zhang, X.; Zhang, M.; Wang, J. Research of node localization algorithm based on wireless sensor networks in marine environment monitoring. J. Comput. Methods Sci. Eng. 2018, 18, 69-83. [CrossRef]

53. Yang, X.; Ong, K.G.; Dreschel, W.R.; Zeng, K.; Mungle, C.S.; Grimes, C.A. Design of a wireless sensor network for long-term, in-situ monitoring of an aqueous environment. Sensors 2002, 2, 455-472. [CrossRef]

54. Seders, L.A.; Shea, C.A.; Lemmon, M.D.; Maurice, P.A.; Talley, J.W. Lakenet: An integrated sensor network for environmental sensing in lakes. Environ. Eng. Sci. 2007, 24, 183-191. [CrossRef]

55. Regan, F.; Lawlor, A.; Flynn, B.O.; Torres, J.; Martinez-Catala, R.; O'Mathuna, C.; Wallace, J. A demonstration of wireless sensing for long term monitoring of water quality. In Proceedings of the 2009 IEEE 34th Conference on Local Computer Networks, Zurich, Switzerland, 20-23 October 2009; pp. 819-825.

56. O'Connor, E.; Zhang, D.; Smeaton, A.F.; O'Connor, N.E.; Regan, F. Multi-modal sensor networks for more effective sensing in irish coastal and freshwater environments. In Proceedings of the 2012 Oceans, Hampton Roads, VA, USA, 14-19 October 2012; pp. 1-9.

57. Hadjimitsis, D.G.; Hadjimitsis, M.G.; Themistocleous, K.; Agapiou, A. Integration of micro-sensor technology and remote sensing for monitoring coastal water quality in a municipal beach and other areas in cyprus. In Proceedings of the Remote Sensing for Agriculture, Ecosystems, and Hydrology XI, Berlin, Germany, 1-3 September 2009; p. 74720p.

58. Jin, N.; Ma, R.; Lv, Y.; Lou, X.; Wei, Q. A novel design of water environment monitoring system based on wsn. In Proceedings of the 2010 International Conference on Computer Design and Applications (ICCDA), Qinhuangdao, China, 25-27 June 2010; pp. V2:593-V592:597.

59. Alkandari, A.; Alabduljader, Y.; Moein, S.M. Water monitoring system using wireless sensor network (wsn): Case study of kuwait beaches. In Proceedings of the 2012 Second International Conference on Digital Information Processing and Communications (ICDIPC), Klaipeda City, Lithuania, 10-12 July 2012; pp. 10-15.

60. Adamo, F.; Attivissimo, F.; Carducci, C.G.C.; Lanzolla, A.M.L. A smart sensor network for sea water quality monitoring. IEEE Sens. J. 2015, 15, 2514-2522. [CrossRef]

61. Bromage, M.; Obraczka, K.; Potts, D. Sea-labs: A wireless sensor network for sustained monitoring of coral reefs. In NETWORKING 2007. Ad Hoc and Sensor Networks, Wireless Networks, Next Generation Internet; Springer: Berlin/Heidelberg, Germany, 2007; pp. 1132-1135.

62. Berlian, M.H.; Sahputra, T.E.R.; Ardi, B.J.W.; Dzatmika, L.W.; Besari, A.R.A.; Sudibyo, R.W.; Sukaridhoto, S. Design and implementation of smart environment monitoring and analytics in real-time system framework based on Internet of Underwater Things and Big Data. In Proceedings of the 2016 International Conference on Electronics Symposium (IES), Denpasar, Indonesia, 29-30 September 2016; pp. 403-408.

63. López, M.; Gómez, J.; Sabater, J.; Herms, A. IEEE 802.15. 4 based wireless monitoring of ph and temperature in a fish farm. In Proceedings of the MELECON 2010 15th IEEE Mediterranean electrotechnical conference, Valletta, Malta, 26-28 April 2010; pp. 575-580.

64. Yang, H.; Wu, H.; He, Y. Architecture of wireless sensor network for monitoring aquatic environment of marine shellfish. In Proceedings of the 2009 7th Asian Control Conference (ASCC), Hong Kong, China, 27-29 August 2009; pp. 1147-1151.

65. Leblond, E.; Lazure, P.; Laurans, M.; Rioual, C.; Woerther, P.; Quemener, L.; Berthou, P. The recopesca project: A new example of participative approach to collect fisheries and in situ environmental data. Mercat. Ocean-Q. Newsl. 2010, 40-48.

66. Lloret, J.; Garcia, M.; Sendra, S.; Lloret, G. An underwater wireless group-based sensor network for marine fish farms sustainability monitoring. Telecommun. Syst. 2015, 60, 67-84. [CrossRef]

67. Meera, M.S.; Rao, S.N. Comparative analysis of IoT protocols for a marine IoT system. In Proceedings of the 2018 7th International Conference on Advances in Computing, Communications and Informatics (ICACCI), Bangalore, India, 19-22 September 2018; Institute of Electrical and Electronics Engineers Inc.: Bangalore, India, 2018; pp. 2049-2053. 
68. Lloret, J.; Sendra, S.; Garcia, M.; Lloret, G. Group-based underwater wireless sensor network for marine fish farms. In Proceedings of the GLOBECOM Workshops (GC Wkshps), Houston, TX, USA, 5-9 December 2011; pp. 115-119.

69. Marimon, M.C.; Tangonan, G.; Libatique, N.J.; Sugimoto, K. Development and evaluation of wave sensor nodes for ocean wave monitoring. IEEE Syst. J. 2015, 9, 292-302. [CrossRef]

70. Chen, H.; Chen, H.; Xie, L.; Wang, K. Temporal tracking of ocean current field using the underwater acoustic sensor network. In Proceedings of the 2018 OCEANS-MTS/IEEE Kobe Techno-Oceans, Kobe, Japan, 28-31 May 2018; Institute of Electrical and Electronics Engineers Inc.: Kobe, Japan, 2018.

71. Yang, J.; Wen, J.; Jiang, B.; Lv, Z.; Sangaiah, A.K. Marine depth mapping algorithm based on the edge computing in Internet of Things. J. Parallel Distrib. Comput. 2018, 114, 95-103. [CrossRef]

72. Blix, K.; Eltoft, T. Machine learning automatic model selection algorithm for oceanic chlorophyll-a content retrieval. Remote Sens. 2018, 10, 775. [CrossRef]

73. Zhong, Y.; Zhang, L.; Xing, S.; Li, F.; Wan, B. The big data processing algorithm for water environment monitoring of the three gorges reservoir area. Abstr. Appl. Anal. 2014, 2014, 698632. [CrossRef]

74. Addison, P.; Collins, D.; Trebilco, R.; Howe, S.; Bax, N.; Hedge, P.; Jones, G.; Miloslavich, P.; Roelfsema, C.; Sams, M. A new wave of marine evidence-based management: Emerging challenges and solutions to transform monitoring, evaluating, and reporting. ICES J. Mar. Sci. 2017, 75, 941-952. [CrossRef]

75. Belghith, E.H.; Rioult, F.; Bouzidi, M. Acoustic diversity classifier for automated marine big data analysis. In Proceedings of the 2018 30th International Conference on Tools with Artificial Intelligence (ICTAI), Volos, Greece, 5-7 November 2018; IEEE Computer Society: Volos, Greece, 2018; pp. 130-136.

76. Li, Z.; Wang, N.; Li, Y.; Sun, X.; Huo, M.; Zhang, H. Collective efficacy of support vector regression with smoothness priority in marine sensor data prediction. IEEE Access 2019, 7, 10308-10317. [CrossRef]

77. Song, J.H.; Xie, H.; Feng, Y. Correlation analysis method for ocean monitoring big data in a cloud environment. J. Coast. Res. 2018, 24-28.

78. Radeta, M.; Nunes, N.J.; Vasconcelos, D.; Nisi, V. Poseidon-Passive-acoustic ocean sensor for entertainment and interactive data-gathering in opportunistic nautical-activities. In Proceedings of the 2018 Designing Interactive Systems Conference (DIS), Hong Kong, China, 9-13 June 2018; Association for Computing Machinery, Inc.: Hong Kong, China, 2018; pp. 999-1012.

79. Coutinho, R.W.; Boukerche, A.; Vieira, L.F.; Loureiro, A.A. Underwater wireless sensor networks: A new challenge for topology control-based systems. ACM Comput. Surv. (CSUR) 2018, 51, 19. [CrossRef]

80. Gkikopouli, A.; Nikolakopoulos, G.; Manesis, S. A survey on underwater wireless sensor networks and applications. In Proceedings of the 2012 20th Mediterranean Conference on Control \& Automation (MED), Barcelona, Spain, 3-6 July 2012; pp. 1147-1154.

81. Felemban, E.; Shaikh, F.K.; Qureshi, U.M.; Sheikh, A.A.; Qaisar, S.B. Underwater sensor network applications: A comprehensive survey. Int. J. Distrib. Sens. Netw. 2015, 1-14. [CrossRef]

82. Domingo, M.C. An overview of the Internet of Underwater Things. J. Netw. Comput. Appl. 2012, 35, 1879-1890. [CrossRef]

83. Kim, S.; Park, S.; Yoo, Y. Dynamic transmission power control based on exact sea surface movement modeling in underwater acoustic sensor networks. In Proceedings of the 2014 IEEE 10th International Conference on Wireless and Mobile Computing, Networking and Communications (WiMob), Larnaca, Cyprus, 8-10 October 2014; pp. 666-672.

84. Bai, W.; Wang, H.; Shen, X.; Zhao, R. Link scheduling method for underwater acoustic sensor networks based on correlation matrix. IEEE Sens. J. 2015, 16, 4015-4022. [CrossRef]

85. Su, R.; Venkatesan, R.; Li, C. An energy-efficient asynchronous wake-up scheme for underwater acoustic sensor networks. Wirel. Commun. Mobile Comput. 2016, 16, 1158-1172. [CrossRef]

86. Coutinho, R.W.; Boukerche, A.; Vieira, L.F.; Loureiro, A.A. Modeling the sleep interval effects in duty-cycled underwater sensor networks. In Proceedings of the 2016 IEEE International Conference on Communications (ICC), Kuala Lumpur, Malaysia, 22-27 May 2016; pp. 1-6.

87. Khan, F.A.; Khan, S.A.; Turgut, D.; Boloni, L. Optimizing resurfacing schedules to maximize value of information in uwsns. In Proceedings of the 2016 IEEE Global Communications Conference (GLOBECOM), Washington, DC, USA, 4-8 December 2016; pp. 1-5.

88. Coutinho, R.W.; Boukerche, A.; Vieira, L.F.; Loureiro, A.A. A novel void node recovery paradigm for long-term underwater sensor networks. Ad Hoc Netw. 2015, 34, 144-156. [CrossRef] 
89. Faheem, M.; Tuna, G.; Gungor, V.C. Qerp: Quality-of-service (qos) aware evolutionary routing protocol for underwater wireless sensor networks. IEEE Syst. J. 2018, 12, 2066-2073. [CrossRef]

90. Javaid, N.; Cheema, S.; Akbar, M.; Alrajeh, N.; Alabed, M.S.; Guizani, N. Balanced energy consumption based adaptive routing for IoT enabling underwater wsns. IEEE Access 2017, 5, 40-51. [CrossRef]

91. Alageswaran, R.; Swapna, P. Enhanced dynamic duty cycled multiple rendezvous multi-channel media access control (dmm-mac) protocol for underwater sensor network based marine eco system. Biomed. Res. 2016, 118-122.

92. Knight, C.; Davidson, J.; Behrens, S. Energy options for wireless sensor nodes. Sensors 2008, 8, 8037-8066. [CrossRef]

93. Javaid, N.; Sher, A.; Nasir, H.; Guizani, N. Intelligence in IoT-based 5G networks: Opportunities and challenges. IEEE Commun. Mag. 2018, 56, 94-100. [CrossRef]

94. Salman, T.; Jain, R. Networking protocols and standards for Internet of Things. 2017. Available online: https: / / onlinelibrary.wiley.com/doi/abs/10.1002/9781119173601.ch13 (accessed on 17 March 2019). [CrossRef]

95. Vidales, M. 802.15.4 Wireless for Internet of Things Developers. Available online: https://blog.helium.com/ 802-15-4-wireless-for-internet-of-things-developers-1948fc313b2e (accessed on 17 March 2019).

(C) 2019 by the authors. Licensee MDPI, Basel, Switzerland. This article is an open access article distributed under the terms and conditions of the Creative Commons Attribution (CC BY) license (http:/ / creativecommons.org/licenses/by/4.0/). 